\title{
Educação Ambiental e a Interdisciplinariedade Como Potencializadores Da Gestão Ambiental
}

\author{
Environmental Education and Interdisciplinarity As boosters Environmental Management
}

\author{
Denise Silva Nunes', Cibelle Machado Carvalho² \\ 1:2Mestranda, Universidade Federal de Santa Maria, Santa Maria, Brasil
}

\section{Resumo}

O presente trabalho objetiva analisar a 'interdisciplinaridade' e a educação ambiental como potencializadores da gestão ambiental. A problemática da pesquisa consiste na falta de percepção sobre a execução da gestão ambiental contemplada com interdisciplinaridade, o que permitirá melhores resultados, seja no âmbito empresarial ou na Administração Pública. As questões ambientais enquadram-se numa perspectiva interdisciplinar e, desse modo, promover a gestão com o planejamento e uso sustentável dos recursos, implica em agregar uma política do conhecimento, que promova a articulação de ciências e a integração de saberes. Nesse sentido, destaca-se a interdisciplinaridade, enquanto política de integração do conhecimento e de cidadania, a ser agregada na gestão ambiental, a fim de reformular estratégias à nova racionalidade ambiental direcionada à sustentabilidade. A metodologia utilizada no presente estudo foi descritiva, com o método dedutivo de abordagem, através da técnica de pesquisa bibliográfica, com a análise de artigos científicos, periódicos, consulta à legislação, livros e revistas. Como resultado final, destaca-se que, a gestão ambiental necessita da participação social na administração das questões ambientais. Através da educação ambiental e da interdisciplinaridade, enquanto estratégias de cidadania é possível potencializar a gestão ambiental.

Palavras-chave: Educação ambiental; Gestão; Interdisciplinaridade; Meio ambiente.

\begin{abstract}
This paper aims to analyze the 'interdisciplinary' environmental education and environmental management as boosters. The research problem is the lack of awareness on the implementation of environmental management awarded interdisciplinarity, which will allow better results, whether in business or public administration framework. Environmental issues fall within an interdisciplinary perspective and thereby promote management with planning and sustainable use of resources implies adding a knowledge policy that promotes the articulation of science and the integration of knowledge. In this sense, there is interdisciplinarity, as an integration of knowledge and citizenship policy, to be aggregated in environmental management in order to reformulate strategies to new environmental rationality directed toward sustainability. The methodology used in this study was descriptive and deductive method approach, using the technique of literature, the analysis of scientific, journals articles, query legislation, books and magazines. As a final result, it is emphasized that the environmental management needs of social participation in the management of environmental issues. Through environmental education and interdisciplinarity, while strategies citizenship can enhance environmental management.
\end{abstract}

Keywords: Environmental education; Management; Interdisciplinarity; Environment. 


\section{INTRODUÇÃO}

A problemática ambiental afeta as condições de sustentabilidade do Planeta, de modo que é necessário internalizar as bases ecológicas e os princípios jurídicos e sociais para a gestão adequada e democrática dos recursos naturais, bem como a cidadania e a comunhão de saberes.

O planejamento do uso sustentável dos recursos naturais implica na necessidade de uma política de conhecimento, numa discussão filosófica que promova a integração de saberes. Nessa perspectiva, destaca-se a importância da interdisciplinaridade como estratégia a ser agregada na gestão ambiental.

A educação para a gestão tem o propósito de contemplar o conhecimento legal e metodológico para uma atuação técnica e social interativa, cooperativa, consciente e qualificada nos processos sociais de planejamento e gestão do território, junto aos colegiados de: bacias hidrográficas, unidades de conservação, municípios, estados e união, tais como: comitês, conselhos, fóruns e comissões (PALAVIZINI, 2011, p.30).

Na perspectiva da empresa, a gestão ambiental pode ser encarada como uma função gerencial global que trata, determina e implementa uma política de meio ambiente na organização. A gestão da empresa passa a incluir, em seus planos e metas, as externalidades advindas de sua atividade. $\mathrm{O}$ setor produtivo absorve a responsabilidade pela melhoria das condições da sua área de atuação, não somente como resultado de pressões exercidas pelos agentes sociais e instituições, mas também como código de conduta voluntário, criado geralmente por instituições que congregam representantes de vários setores industriais (TEIXEIRA; BESSA, 2009, p.5).

Com isso, a mudança de paradigmas requer uma expansão não apenas de nossas percepções e maneiras de pensar, mas também de nossos valores. Nesse sentido, um dos desafios para a concretização da sustentabilidade consiste na percepção da problemática ambiental a partir de sua complexidade e da comunicação ecológica, agregadas aos fatores econômicos, políticos, sociais e culturais. Ainda, nas questões de participação dos cidadãos na esfera pública, de modo a proporcionar uma melhor e eficaz gestão ambiental.

A degradação ambiental foi desencadeada, inclusive, pela inadequada apropriação dos recursos naturais, pela falta de racionalidade e equilíbrio meio ambiente e progresso. A problemática ambiental, de modo geral, consiste na atual racionalidade a qual engendrou a ciência moderna como dominação da natureza, bem como produziu a economização do mundo e implantou a lei globalizadora do mercado, por meio do sistema capitalista.

Nesse sentido, é necessário sair da racionalidade dominante e buscar novos caminhos para se observar a questão ambiental, e é nesse momento que a interdisciplinaridades abre horizonte para novas perspectivas propositivas ambientalmente.

É importante que mecanismos de comando e controle de gestão ambiental sejam utilizados conjuntamente, através de uma conduta empresarial mais responsável e comprometida com as condições ambientais adequadas para o bem-estar social. Destaca-se, também nessa perspectiva, a conscientização da importância da gestão e da atuação conjunta entre poder público e sociedade.

\section{METODOLOGIA}

A metodologia empregada é uma pesquisa descritiva, que parte de uma pesquisa bibliográfica baseada em livros, artigos científicos, periódicos eletrônicos e legislação aplicada. A estratégia geral da pesquisa foi o levantamento e análise de informações na literatura técnico-científica sobre gestão ambiental, buscando as contribuições da interdisciplinaridade e da educação ambiental.

\section{RESULTADOS E DISCUSSÕES}

Enquanto discussões do presente estudo pauta-se em dois aspectos principais, quais sejam: "Conexões entre cidadania, gestão e participação", e, "a importância da interdisciplinaridade na problemática ambiental", conforme a seguir. 


\section{I. ConeXões ENTRE CIDADANIA, GeSTÃo E PARTICIPAÇÃo}

A Conferência Mundial sobre o Meio Ambiente Humano, celebrada em Estocolmo no ano de 1972, demonstrou a necessidade de gerar um amplo processo de educação ambiental, o que levou a criar, no ano de 1975, o Programa Internacional de Educação Ambiental da UNESCO. O Programa foi estruturado nos princípios da ética, da sustentabilidade ecológica, da equidade social, da reconstituição do conhecimento e com base na interdisciplinaridade enquanto principio metodológico privilegiado da educação ambiental.

A Constituição da República Federativa do Brasil de 1988 impôs ao Poder Público e à coletividade o dever de defender e preservar o ambiente para as presentes e futuras gerações. O artigo 225 do texto constitucional consagra "a ética da solidariedade entre as gerações, pois as gerações presentes não podem usar o meio ambiente fabricando a escassez e a debilidade para as gerações vindouras" (MACHADO, 2010, p.136).

O desenvolvimento sustentável é um projeto social e político que aponta para ordenamento ecológico e a descentralização territorial da produção, assim como para a diversificação dos tipos de desenvolvimento e dos modos de vida das populações que habitam o planeta (LEFF, 2001, p.57). Desse modo, implicando no processo de democratização da sociedade à participação na apropriação e transformação de seus recursos ambientais, gestão dos riscos e tomada de decisões.

A gestão ambiental participativa propõe, além da oportunidade de reverter os custos ecológicos e sociais da crise econômica e ecológica, a possibilidade de integrar a população marginalizada num processo de produção para satisfazer suas necessidades fundamentais, aproveitando o potencial ecológico de seus recursos ambientais e respeitando suas identidades coletivas.

Assim, sendo, o autor Enrique Leff elenca princípios como condições de uma gestão democrática do desenvolvimento sustentável, tais como: a equidade social, a diversidade cultural, o equilíbrio regional, a autonomia e capacidade de autogestão das comunidades e a pluralidade de tipos de desenvolvimento (LEFF, 2001, p.63).

Quanto às políticas para a sustentabilidade no ambiente urbano, por exemplo, faz-se necessário, inclusive, observar a gestão ambiental da cidade, a qual necessita da conjugação da democracia, cidadania e participação, como princípios norteadores para uma gerência administrativa direcionada às questões socioambientais do espaço urbano.

Na perspectiva da administração pública na gestão ambiental, deve aquela primar pelos princípios administrativos dispostos no texto constitucional, visto que o meio ambiente é um bem difuso. Conforme caput do art.37, CF/88, "a administração pública direta e indireta de qualquer dos poderes da União, dos Estados, do Distrito Federal e dos Municípios obedecerá aos princípios de legalidade, impessoalidade, moralidade, publicidade e eficiência".

A Constituição Federal no seu art. 225, $§ 1^{\circ}$, VI, dispõe que "incumbe ao Poder Público promover a educação ambiental em todos os níveis de ensino e a conscientização pública para a preservação do meio ambiente".

Frisa-se que a Lei no 9.795/1999 institui a educação ambiental no Brasil, e, conforme disposto no seu artigo $1^{\mathrm{o}}$, envolve os processos por meio dos quais o indivíduo e a coletividade constroem valores sociais, conhecimentos, habilidades, atitudes e competências voltadas para a conservação do meio ambiente, bem de uso comum do povo, essencial à sadia qualidade de vida e sua sustentabilidade.

A 'educação ambiental' tem como principal finalidade formar (ou capacitar) o cidadão para uma relação respeitosa e saudável com os ecossistemas, com a Biosfera e com o Planeta Terra, valorizando a diversidade ecológica e cultural, na perspectiva da construção de um mundo pacífico e sustentável (PALAVIZINI, 2011, p.27).

Os projetos de Educação para a Sustentabilidade devem prever a estrutura de avaliação em três estratégias: a Avaliação de Processo; a Avaliação de Resultados; e a Avaliação de Impacto (PALAVIZINI, 2011, p.33).

Os valores ambientais surgem contra a cultura do poder fundado na razão tecnológica e na racionalidade econômica. Desse modo, a ética ambiental visa promover uma mudança de atitudes, associada à transformação dos conhecimentos teóricos e práticos nos quais se funda a racionalidade social e produtiva dominante.

Com isso, a constituição de uma racionalidade ambiental e a transição para um futuro sustentável, para o autor Enrique Leff, exigem mudanças sociais que transcendem o confronto entre duas lógicas (econômica e ecológica) opostas: 
É um processo político que mobiliza a transformação de ideologias teóricas, instituições políticas, funções governamentais, normas jurídicas e valores culturais de uma sociedade que se insere na rede de interesses de classes, grupos e indivíduos que mobilizam as mudanças históricas, transformando os princípios que regem a organização social. [...] A busca do bem comum com a intervenção do Estado e a participação da sociedade civil num processo de reapropriação da natureza, orientando seus valores e potenciais para um desenvolvimento sustentável e democrático (LEFF, 2001, p.143).

Com isso, a mudança de paradigmas requer uma expansão não apenas de nossas percepções e maneiras de pensar, mas também de nossos valores. Nessa perspectiva, um dos desafios para a concretização de cidades sustentáveis consiste na participação dos cidadãos na esfera pública, de modo a proporcionar uma melhor e eficaz gestão ambiental.

A autora Hannah Arendt aborda a questão do homem no espaço público e privado, e para ela, "o que torna tão difícil suportar a sociedade de massas não é o número de pessoas que ela abrange, ou pelo menos não é este o fator fundamental; antes, é o fato de que o mundo entre elas perdeu a força de mantê-las juntas, de relacioná-las umas às outras" (ARENDT, 2005, p.61-65).

Ainda, no entendimento de Arendt, no espaço comunitário e na esfera pública, a questão de 'ser visto e ouvido por outros' é importante devido à existência de ângulos diferentes. E se o mundo deve conter um espaço público, não pode ser construído apenas para uma geração e planejado somente para os que estão vivos. Desse modo, a necessidade de reunir a comunidade no espaço público pelo bem comum, por um motivo e objetivo comum a todos. E nesse contexto, o meio ambiente, enquanto bem difuso e de uso comum do povo, aparece como pauta a ser discutida por todos.

A participação cidadã requer a aproximação das 'informações ambientais'. E nesse sentido, o autor Henri Acselrad entende que a falta de informação ambiental favorece os responsáveis pela produção dos riscos, pois, "com a desinformação torna-se incerta a percepção da relação de causalidade entre a ação dos empreendimentos sobre o meio e os riscos produzidos para as populações" (ACSELRAD, 2009, p.81).

A gestão ambiental participativa propõe, além da oportunidade de reverter os custos ecológicos e sociais da crise econômica e ecológica, a possibilidade de integrar a população marginalizada num processo de produção para satisfazer suas necessidades fundamentais, aproveitando o potencial ecológico de seus recursos ambientais e respeitando suas identidades coletivas.

A 'expropriação dos sentidos' da população atingida, muitas vezes, resulta da 'desinformação organizada' por um bloco de interesses que diz considerar essa contaminação como um 'mal necessário do desenvolvimento'. A 'cegueira' dos cidadãos é trabalhada institucionalmente a fim de evitar a localização dos riscos sobre os setores sociais mais capazes de serem ouvidos na esfera pública.

A cidadania surge como reação à ordem estabelecida, pois, em face à globalização econômica, os movimentos da cidadania legitimam os direitos humanos, configurando novos atores sociais.

A questão ambiental emerge de novos valores e novos princípios que levam à reorganização social e da produção para a reapropriação da natureza e da cultura. Isto implica o estabelecimento de novas relações sociais de produção e de novos sentidos civilizatórios [...]. O poder mais consolidado que deve ser desconstruído é a ideologia neoliberal; é a armadura mais difícil de desarmar, apesar de serem evidentes seus efeitos ecodestrutivos, seu impacto na produção da pobreza, o desmoronamento das instituições e a desmoralização da sociedade. (LEFF, 2001, p.126-127).

O exercício da cidadania é inerente à participação cidadão na gestão pública, e conforme o autor Darcísio Correa "significa a realização democrática de uma sociedade, compartilhada por todos os indivíduos ao ponto de garantir a todo o acesso ao espaço público e condições de sobrevivência digna, tendo como valor-fonte a plenitude da vida" (CORRÊA, 2000, p. 214).

A cidadania, enquanto ação participativa onde há interesse público ou interesse social, conforme o autor Paulo Affonso Leme Machado implica em: "ser cidadão é sair de sua vida meramente privada e interessar-se pela sociedade de que faz parte e ter direitos e deveres para nela influenciar e decidir" (MACHADO, 2010, p.139).

Trata-se de um dos fundamentos do modelo de Estado delineado pelo texto constitucional, 
que pode ser entendida como os vínculos entre o individuo e a organização do poder. A cidadania se relaciona com o conjunto de direitos do cidadão e a sua participação na vida política. Com isso, a participação alicerça a cidadania e pode se concretizar tanto no âmbito individual quanto no âmbito coletivo (COSTA, 2009, p.117).

Desse modo, em face do poder do mercado e do Estado, a cidadania postula o seu direito de participação nos processos de produção, gestão e tomada de decisões em prol da sustentabilidade. Ainda, a observância da ética ambiental a fim de reanimar a "[...] vontade nietzscheana de poder como um desejo de vida que rompe o silêncio, reabrindo os sentidos da história. O saber ambiental é mobilizado por essa vontade de poder querer, que vincula o conhecimento a uma ética do desejo" (LEFF, 2001, p.121).

Feitas estas considerações, na interface 'cidadania, gestão e participação' insere-se o elemento da interdisciplinaridade como um instrumento potencializador da educação ambiental, conforme exposição a seguir.

\subsection{A IMPORTÂNCIA DA INTERDISCIPLINARIDADE NA PROBLEMÁTICA AMBIENTAL}

A problemática ambiental, independente de sua especificidade, possui caráter 'sistêmico-complexo', pois, acabam se interdependentes. Quanto à inter-relação dos sistemas, observa-se a questão da qualidade de vida, em que, conforme o autor Paulo Affonso Leme Machado (2010, p.133), "só pode ser conseguida e mantida se o meio ambiente estiver ecologicamente equilibrado Ter uma sadia qualidade de vida é ter o meio ambiente não poluído".

Quanto às políticas para a sustentabilidade no ambiente urbano, por exemplo, faz-se necessário, inclusive, observar a gestão ambiental da cidade, a qual necessita da conjugação da democracia, cidadania e participação, como princípios norteadores para uma gerência administrativa direcionada às questões socioambientais do espaço urbano.

Observa-se que muitos dos problemas das cidades, como a poluição ambiental, são consequências das interações da relação 'homem-natureza' que, neste aspecto, consideravelmente sem adequação e planejamento ambiental. Conforme o autor sistêmico Fritjof Capra (1996, p.23-25), a percepção ecológica profunda reconhece a interdependência fundamental de todos os fenômenos, e o fato de que, enquanto indivíduos e sociedade nós estamos todos encaixados nos processos cíclicos da natureza (e, em última análise, somos dependentes desses processos).

O ambiente é integrado por processos, tanto de ordem física como social, dominados e excluídos pela racionalidade econômica: a natureza superexplorada e a degradação socioambiental, a perda de diversidade biológica e cultural, a pobreza associada à destruição do patrimônio de recursos dos povos e à dissolução de suas identidades étnicas, a desigual distribuição dos recursos ecológicos do crescimento e a deterioração da qualidade de vida (LEFF, 2001, p.224).

$\mathrm{O}$ crescimento econômico, sem o devido respeito ao direito fundamental ao meio ambiente limpo e ecologicamente sadio, provoca danos irreparáveis ou de difícil reparação (FREITAS, 2012, p.44). E nesse contexto, a educação para a sustentabilidade, conforme entendimento do autor Juarez Freitas, ajuda a compreender as leis naturais e possibilita a escolha do modelo mais adequado ao desenvolvimento intemporal (FREITAS, 2012, p.170).

Conforme o autor José Afonso da Silva o meio ambiente se constitui da "interação do conjunto de elementos naturais, artificiais e inclusive culturais, uma vez que propiciam o desenvolvimento equilibrado da vida em todas as suas formas" (SILVA, 1997, p.2). Com esse entendimento, é possível vislumbrar a conexão entre os elementos que compõe o ecossistema, bem como atribuir a necessidade de se pensar na interdisciplinaridade.

De modo geral, os problemas do espaço urbano, por exemplo, decorrem das transformações geográficas, em que o despertar para a discussão acerca da crise ecológica ocorre "a partir da constatação de que as condições tecnológicas, industriais e formas de organização e gestão da sociedade estão em conflito com a qualidade de vida" (MORATO LEITE, 2003, p.21).

Muitos autores consideram a questão ambiental como 'complexa', e tem caráter eminentemente social: esta foi gerada e está atravessada por um conjunto de processos sociais (LEFF, 2006, p.111). A complexidade emerge como resposta a este constrangimento do mundo e da natureza pela unificação ideológica, tecnológica e econômica (LEFF, 2006, p.195).

Desse como, em face da problemática ambiental, o autor Enrique Leff defende a necessidade de repensar 'o ser no mundo complexo', bem como entender suas vias de complexização para a rea- 
propriação e a reconstrução do mundo (2003, p.20-21).

Aprender a complexidade ambiental implica um processo de desconstrução e reconstrução do pensamento; remete a suas origens, à compreensão de suas causas; a ver os 'erros' da história que se arraigaram em certezas sobre o mundo com falsos fundamentos; a descobrir e reavivar o ser da complexidade que ficou no 'esquecimento' com a cisão entre o ser e o ente (Platão), do sujeito e do objeto (descartes), para aprender o mundo coisificando-o, objetivando-o, homogeneizando-o. Esta racionalidade dominante descobre a complexidade em seus limites, em sua negatividade, na alienação e na incerteza do mundo economizado, arrastado por um processo incontrolável e insustentável de produção (LEFF, 2003, p.16).

Com isso, a problemática ambiental, na sua complexidade, implica em 'aprender a aprender', no questionamento do pensamento, na epistemologia, na compreensão de que a civilização ocidental estabeleceu entre o ser, os entes e as coisas, nas quais o meio ambiente foi submetido, implicando na reformulação da racionalidade ambiental, com outra visão, muito além da racionalidade econômica que produziu a modernidade insustentável.

A problemática ambiental é uma questão interdisciplinar, com isso, o planejamento do uso sustentável dos recursos implica na necessidade de uma política do conhecimento, que promova a articulação de ciências e a integração de saberes das diversas disciplinas.

A problemática ecológica requer um consenso para a proteção do meio ambiente, e, nesse sentido:

$\mathrm{Na}$ teoria da ação comunicativa de Habermas, por sua vez, o sistema adquire a sua identidade a partir da colonização do ambiente, o mundo da vida. Este último seria a fonte da criação histórica. A solução deste problema estaria na possibilidade de se obter um consenso universal na razão prática: um ponto de contato entre a pragmática situacional dos atos de fala e a universalidade transcendente do imperativo categórico da livre argumentação (ROCHA, 2003, p.114).

Desse modo, observa-se o elemento 'consenso' de Habermas, de modo a colaborar no sentido de rever a função do direito, e outros elementos na sociedade complexa, no que tange à propositura de soluções para a questão socioambiental. Também nesse sentido, o autor Leonel Severo Rocha menciona:

É importante falar-se de democracia deliberativa, uma democracia em que todos devem participar da tomada de decisões, como uma utopia necessária para a construção de uma nova sociedade mais ecológica, capaz de superar a nossa etapa atual na América Latina de democracia somente delegativa. A teoria da ação comunicativa fornece instrumentais para uma melhor compreensão da racionalidade democrática (ROCHA, 2003, p.114).

Conforme propõe o autor Leonel Severo Rocha, são fatores que exigem uma revolução epistemológica que, avançando além da racionalidade analítica dominante, aponte para uma racionalidade também pragmático-sistêmica.

Destaca-se que a problemática envolvendo, por exemplo, o espaço urbano também está inserido na forma pela qual o ambiente é compreendido, isto é, a partir de uma visão fragmentada e reducionista do 'meio' ambiente, necessitando de um novo paradigma com direção ao ambiente como um todo. $\mathrm{O}$ autor sistêmico Fritjof Capra, físico austríaco, defende a visão de mundo holística, que conceba o mundo como um todo integrado, e não como uma coleção de partes dissociadas.

Com isso, "quanto mais estudamos os problemas de nossa época, mais somos levados a perceber que eles não podem ser entendidos isoladamente. São problemas sistêmicos o que significa que estão interligados e são interdependentes" (CAPRA, 1996, p.23).

Assim sendo, no equilíbrio e proteção do ambiente é necessária a percepção das interações entre homem e natureza, bem como a observância de uma ciência que considere a complexidade e os riscos ambientais, conjugando a interdisciplinaridade de saberes, contribuindo, dessa forma, na (re) formulação da racionalidade ambiental.

A problemática ambiental é uma questão interdisciplinar, com isso, o planejamento do uso sustentável dos recursos implica na necessidade de uma política do conhecimento, que promova a articulação de ciências e a integração de saberes das diversas disciplinas. 
Além do propósito de gerar um paradigma oniabrangente, de 'ecologizar' o saber ou de formular uma metodologia geral para o desenvolvimento do conhecimento, o saber ambiental problematiza o conhecimento, mas sem desconhecer a especificidade das diferentes ciências historicamente constituídas, ideologicamente legitimadas e socialmente institucionalizadas (LEFF, 2006, p.208).

A 'interdisciplinaridade' proposta pelo 'saber ambiental' implica a integração de processos naturais e sociais de diferentes ordens de materialidade e esferas de racionalidade. Nesse âmbito, o diálogo de saberes trata-se de "uma comunicação entre seres constituídos e diferenciados por seus saberes" (LEFF, 2006, p.383).

A interdisciplinaridade possibilita o diálogo entre diversas áreas do conhecimento, o que possibilita uma melhor compreensão e proteção ambiental. Nessa perspectiva, a educação ambiental é potencializada pela interdisciplinaridade, pois, abre-se um novo horizonte, com diversas possibilidades para se pensar, observar, administrar e executar políticas (de cidadania) adequadas para o meio ambiente.

\section{CONCLUSÃO}

A presente pesquisa analisou a 'interdisciplinaridade' e a educação ambiental como ferramentas potencializadoras da gestão ambiental. Foram feitas conexões entre cidadania, educação, gestão e participação.

Com o presente estudo foi possível compreender que a problemática ambiental não reside apenas nas políticas neoliberais e no problema da distribuição do poder e da renda, da propriedade formal da terra e dos meios de produção. Mas, também reside na questão da participação democrática da sociedade na gestão de seus recursos e potenciais, bem como nos processos de tomada de decisões sobre a sustentabilidade ecológica.

Foi possível analisar gestão ambiental potencializada com a interdisciplinaridade e com a educação ambiental, na medida em que estas possibilitam integrar valores ambientalmente éticos e promover escolhas e decisões direcionadas para a sustentabilidade.

Quanto à gestão ambiental, com base na sustentabilidade e participação social, há de se observar a racionalidade ambiental nas articulações das ciências e nas estratégias de manejo e utilização dos recursos naturais. Também deve ser observada a comunicação ecológica entre os elementos constitutivos do meio ambiente.

Quanto à perspectiva da sustentabilidade, verificou-se que são necessárias políticas educativas, de ciência e tecnologia que agreguem conhecimentos, capacidades e habilidades em prol de um processo endógeno de desenvolvimento sustentável.

Pensar no diálogo de saberes remete à necessidade de internalizar um saber ambiental emergente em todo um conjunto de disciplinas, tanto das ciências naturais como nas ciências sociais, para a compreensão dos fenômenos socioambientais.

A interdisciplinaridade (ambiental) possibilita uma análise integrada das bases materiais, dos instrumentos técnicos e legais. Também possibilita melhor desempenho das ações e programas, de forma a orientar, com base na equidade, na reapropriação social da natureza e na gestão ambiental do desenvolvimento.

$\mathrm{Na}$ gestão ambiental a interdisciplinaridade possibilita a construção de uma ética baseada no reconhecimento e respeito da outridade, na diversidade e na diferença, sobretudo destacando a interdisciplinaridade na observância da comunicação ecológica direcionada para a proteção do meio ambiente.

\section{REFERÊNCIAS}

ACSELRAD, Henri. O que é justiça ambiental. Rio de Janeiro: Garamond, 2009;

ARENDT, Hannah. A condição humana. Trad. Roberto Raposo. 10. ed. Rio de Janeiro: Forense Universitária, 2005; 


\section{NUNES; CARVALHO}

BRASIL. Constituição da República Federativa do Brasil. Disponível em <http://www.planalto.gov.br/ccivil_03/constituicao/constituicaocompilado.htm> Acesso: 24/04/2014.

Lei No 9.795, de 27 de abril de 1999. Dispõe sobre a educação ambiental, institui a Política Nacional de Educação Ambiental e dá outras providências. Disponível em < http://www.planalto.gov.br/ccivil 03/leis/ 19795.htm> Acesso: 24/04/2014.

CAPRA, Fritjof. A teia da vida: uma nova compreensão científica dos sistemas vivos. São Paulo: Editora Cultrix, 1996;

CORRÊA, Darcísio. A construção da cidadania: reflexões histórico-políticas. Ijuí: UNIJUÍ, 2000

COSTA, Marli Marlene Moraes; REIS, Suzéte da Silva. Em busca de uma cidadania ambiental: possibilidades e perspectivas a partir da educação ambiental. In. Estudos Ambientais: livro em homenagem ao professor João Telmo Vieira. REIS, Jorge Renato dos; WEBER, Eliana; BITENCOURT, Caroline Müller (Orgs.). Porto Alegre: [s.c.p.], 2009;

FREITAS, Juarez. Sustentabilidade: Direito ao futuro. 2.ed. Belo Horizonte: Fórum, 2012.

LEFF, Enrique. Racionalidade ambiental: a reapropriação social da natureza. Trad. Luís Carlos Cabral. Rio de Janeiro: Civilização Brasileira, 2006;

Pensar a complexidade ambiental. In. La complejidad ambiental. Coord. Enrique Leff. São Paulo: Editora Cortez, 2003;

Epistemologia ambiental. Trad. Sandra Valenzuela. 4.ed. São Paulo: Cortez, 2006;

Saber ambiental: sustentabilidade, racionalidade, complexidade, poder. Trad. Lúcia Mathilde Orth. Petrópolis, RJ: Vozes, 2001;

LEITE. José Rubens Morato. Dano ambiental: do indivíduo ao coletivo extrapatrimonial. São Paulo: Revista dos Tribunais, 2000;

MACHADO, Paulo Affonso Leme. Direito ambiental brasileiro. 18.ed. rev. atual. São Paulo: Malheiros Editores, 2010;

MORATO LEITE, José Rubens. Dano ambiental: do individual ao coletivo extrapatrimonial. São Paulo: RT, 2003;

PALAVIZINI, Roseane. Educação para a sustentabilidade: uma abordagem transdisciplinar. NUPEAT-IESAUFG, v.1, n.1, jan./jun./2011 (p.25-35).

ROCHA, Leonel Severo. Epistemologia jurídica e democracia. São Leopoldo: Ed.UNISINOS, 2003;

SILVA, José Afonso da. Direito Ambiental Constitucional. 2 ed. São Paulo: Maleiros, 1997; 